Gut, 1988, 29, 44-48

\title{
Sorbitol malabsorption in normal volunteers and in patients with coeliac disease
}

\author{
G R CORAZZA, A STROCCHI, R ROSSI, D SIROLA, AND G GASBARRINI \\ From the I Department of Medical Pathology, University of Bologna and Medical School, Bologna, Italy
}

SUMMARY Sorbitol is a hexahydroxy alcohol used as a sugar substitute in many dietetic foods and as a drug vehicle. Previous studies have suggested that sorbitol ingestion may be an additional cause of non-specific gastrointestinal distress. We evaluated sorbitol malabsorption in 30 healthy volunteers, seven patients with untreated coeliac disease and nine patients with coeliac disease on a gluten free diet, using a four hour $\mathrm{H}_{2}$ breath test. After ingestion of test solutions containing sorbitol 10 and $20 \mathrm{~g}$ and of four sweets $(6 \cdot 8 \mathrm{~g}$ sorbitol $), 90 \%, 100 \%$, and $62 \%$ of healthy volunteers, respectively had significantly raised $\mathrm{H}_{2}$ excretion, indicating malabsorption of sorbitol. Of all healthy subjects tested, $45 \%$ after $10 \mathrm{~g}, 100 \%$ after $20 \mathrm{~g}$, and $50 \%$ after four sweets complained of symptoms of carbohydrate intolerance during the eight hours after sorbitol. After a $5 \mathrm{~g}$ dose given at concentrations of $2 \%, 4 \%, 8 \%, 16 \%$, malabsorption was shown in $10 \%, 12 \%, 22 \%$, and $43 \%$ of the healthy volunteers. Symptoms of intolerance at $5 \mathrm{~g}$ were experienced only at concentrations of $8 \%$ and $16 \%$. Unlike healthy volunteers and coeliac patients on a gluten free diet, $100 \%$ of untreated coeliacs malabsorbed a $2 \%$ solution of $5 \mathrm{~g}$ sorbitol. These results show that malabsorption and intolerance of sorbitol may result from ingestion of doses and/or concentrations usually found in many foods and drugs; they underline the need to consider this as a possible and hitherto underestimated cause of gastrointestinal symptoms.

Sorbitol, a hexahydroxy sugar alcohol occurring naturally in many fruits, ${ }^{1.3}$ is produced synthetically for commercial purposes by the catalytic reduction of glucose. Sorbitol is only partially absorbed, ${ }^{+5}$ does not produce a rise in blood sugar when taken by mouth ${ }^{6}$ and because of its sweetening power ${ }^{7}$ it is widely used as a sugar substitute in dietetic food and beverages and as a vehicle for suspending active drugs.

Recent studies, based on breath hydrogen $\left(\mathrm{H}_{2}\right)$ analysis, have shown that the majority of healthy adults malabsorb sorbitol ${ }^{*-10}$ and this is held to be the cause of functional bowel complaints after ingestion of sorbitol contained in sweets, " chewing-gum, ${ }^{1213}$ dietetic food, ${ }^{14}$ and drugs. ${ }^{15}$

As sorbitol can be found in a number of commercial products at high concentration, we studied

Address for correspondence: G R Corazza, MD, I Patologia Medica. Nuove Patologie. Policlinico S. Orsola, Via Massarenti 9, 40138 Bologna, Italy. Received for publication 2 July 1987. the effect of varying amounts and concentrations of this substance on its malabsorption and intolerance in healthy volunteers and in patients with coeliac disease.

\section{Methods}

SUBJECTS

Thirty healthy volunteers, 15 women and 15 men, ranging in age from 22 to 61 years (mean $27 \pm 7$ ), with no history of recent or recurrent gastrointestinal symptoms, recent antibiotic use, or diagnosis of gastrointestinal disease, took part in the study. Seven biopsy diagnosed untreated coeliac patients and nine coeliac patients on a gluten free diet were also studied. Informed consent was obtained from all the subjects taking part in the study.

TEST SOLUTIONS

All healthy volunteers were tested, on a single blinded basis, after an overnight fast, with two or 
more of the following solutions: $20 \mathrm{~g}$ in $250 \mathrm{ml}$ water $(8 \%$ solution; $447 \mathrm{mOsm} / \mathrm{kg}), 10 \mathrm{~g}$ in $250 \mathrm{ml}$ water ( $4 \%$ solution; $224 \mathrm{mOsm} / \mathrm{kg}$ ), and $5 \mathrm{~g}$ in $250 \mathrm{ml}$ water ( $2 \%$ solution; $123 \mathrm{mOsm} / \mathrm{kg}$ ). Five grams were also administered in $125,62.5$, and $31.2 \mathrm{ml}$ water $(4 \%$, $8 \%$, and $16 \%$ solution, respectively with corresponding osmolality of 221,428 , and $973 \mathrm{mOsm} / \mathrm{kg}$ ). Eight healthy volunteers were also tested after having eaten two and four sweets each containing $1.7 \mathrm{~g}$ sorbitol. Untreated and treated coeliacs were tested with $5 \mathrm{~g}$ sorbitol in $250 \mathrm{ml}$ water ( $2 \%$ solution). Serial testing was done at least two days apart. All subjects were known to be capable of producing $\mathrm{H}_{2}$ after ingestion of $10 \mathrm{~g}$ lactulose.

All subjects were asked to report symptoms such as bloating, abdominal pain, and diarrhoea which may have occurred during the eight hour period after sorbitol ingestion. Subjects who had experienced at least one of these symptoms were defined as sorbitol intolerant.

BREATH $\mathrm{H}_{2}$ TESTING

End expiratory breath samples were collected before and at 30 min intervals for four hours after ingestion of the test sugar solution. Samples were tested for $\mathrm{H}_{2}$ concentration with a gas chromatograph (Microlyzer Model 12, Quintron, Milwaukee, WI, USA) and

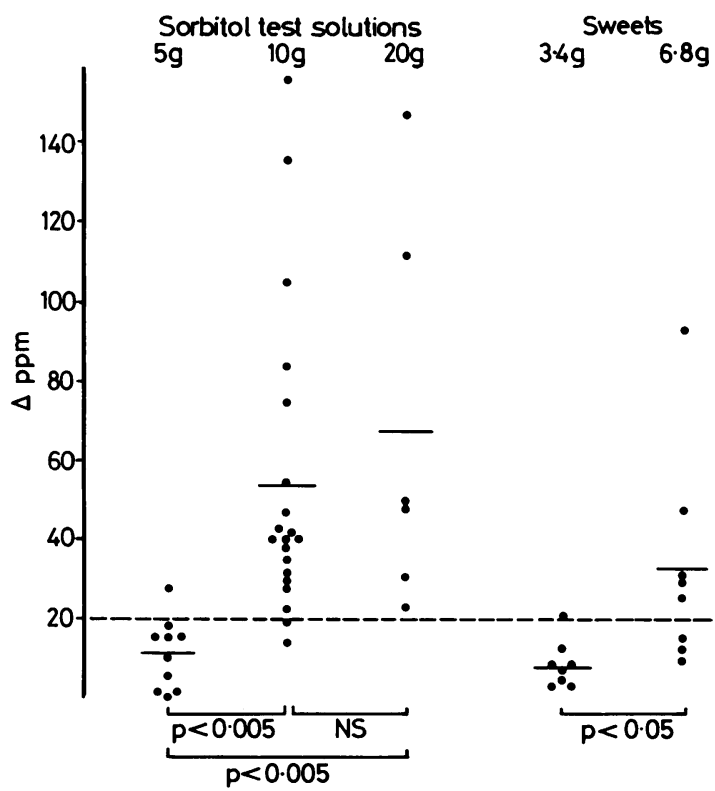

Fig. 1 Maximum increase in breath hydrogen concentration over fasting baseline ( $\Delta$ ppm) in healthy volunteers after the ingestion of 5,10 , and $20 \mathrm{~g}$ sorbitol in 250 $\mathrm{ml}$ water and two and four sweets containing 3.4 and $6.8 \mathrm{~g}$ sorbitol, respectively. Values above the dotted line indicate sorbitol malabsorption.

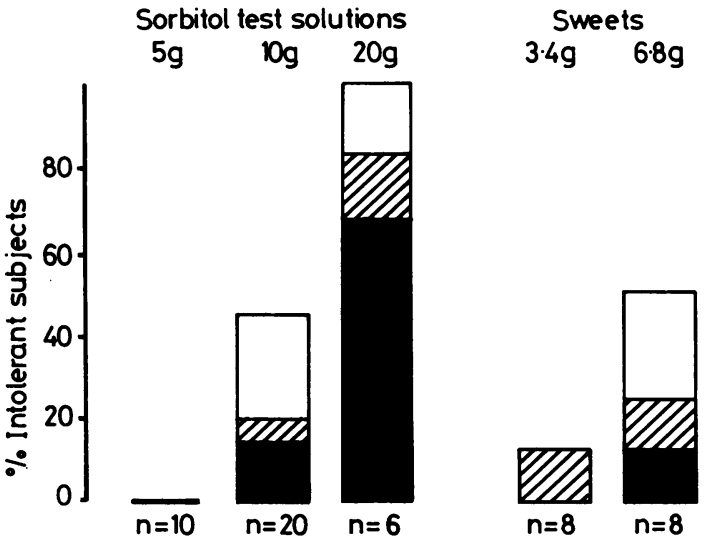

Fig. 2 Percentage of intolerant subjects after ingestion of 5 , 10 , and $20 \mathrm{~g}$ sorbitol in $250 \mathrm{ml}$ water and two and four sweets containing 3.4 and $6 \cdot 8 \mathrm{~g}$ sorbitol, respectively. Black bars: subjects with bloating, cramps and diarrhoea; shadowed bars: subjects with bloating and cramps; white bars: subjects with only bloating.

results were expressed in parts per million (ppm). A rise of at least $20 \mathrm{ppm}$ over fasting baseline was considered evidence of sorbitol malabsorption. The cumulative $\mathrm{H}_{2}$ excretion, over the four hour test, was estimated by calculating the area under the curve of $\mathrm{H}_{2}$ concentration against time with the equation for the sum of the areas of consecutive trapezoids as proposed by Kotler $e t$ al. ${ }^{16}$

STATISTICAL ANALYSIS

The results were statistically analysed by the Student's $t$ test and the linear correlation test.

\section{Results}

The rise in breath $\mathrm{H}_{2}$ concentration over baseline $(\Delta \mathrm{ppm})$ after the ingestion of 5,10 , and $20 \mathrm{~g}$ sorbitol in $250 \mathrm{ml}$ water and two sweets containing $3.4 \mathrm{~g}$ sorbitol and four sweets containing $6.8 \mathrm{~g}$ sorbitol is shown in Figure 1. After ingestion of both $10 \mathrm{~g}$ and $20 \mathrm{~g}$ the mean $\Delta \mathrm{ppm}$ was significantly higher than after ingestion of $5 \mathrm{~g}$. Although the mean rise in breath $\mathrm{H}_{2}$ concentration was higher after $20 \mathrm{~g}$ than after $10 \mathrm{~g}$, no significant difference was found between these two groups. The ingestion of four sweets $(6.8 \mathrm{~g})$ caused an increase in breath $\mathrm{H}_{2}$ excretion significantly higher than after two sweets $(3.4 \mathrm{~g})$.

Sorbitol malabsorption was found in one of 10 healthy volunteers $(10 \%)$ after $5 \mathrm{~g}$ solution, 18 of 20 $(90 \%)$ after $10 \mathrm{~g}$ solution, six of $6(100 \%)$ after $20 \mathrm{~g}$ solution, one of $8(12 \%)$ after two sweets, and five of $8(62 \%)$ after four sweets. A rise $\geq 20 \mathrm{ppm}$ in breath $\mathrm{H}_{2}$ excretion was observed as early as $\mathbf{3 0} \mathrm{min}$ and as late as $\mathbf{1 1 0} \mathrm{min}$ after sorbitol ingestion. 
The proportion of intolerant subjects rose with increases of sorbitol doses and concentrations (Fig. 2 ). All but one of the intolerant subjects were malabsorbers but the malabsorbers were not all intolerant.

Figure 3 shows that there was no significant difference in mean $\Delta \mathrm{ppm}$ values after administration of $5 \mathrm{~g}$ solution of sorbitol at different concentrations. While only one subject of $10(10 \%)$ was shown to malabsorb a $2 \%$ solution, however, one of eight $(12 \%)$, two of nine $(22 \%)$, and three of seven $(43 \%)$ were shown to malabsorb $5 \mathrm{~g}$ of sorbitol in $4 \%, 8 \%$, and $16 \%$ solution, respectively. Only one subject after $8 \%$ solution and two subjects after $16 \%$ solution experienced symptoms of intolerance.

Five grams in a $2 \%$ solution were also given to seven untreated coeliacs and nine coeliacs on a gluten free diet. As shown in Figure 4, excretion of $\mathrm{H}_{2}$ was significantly higher in untreated coeliacs than in both healthy volunteers and treated coeliacs. No significant difference was found between healthy volunteers and coeliac patients on a gluten free diet. It was not possible to evaluate intolerance in the untreated coeliacs as most of them already suffered from the symptoms that we attribute to carbohydrate malabsorption.

A significant correlation between $\Delta$ ppm values and cumulative $\mathrm{H}_{2}$ excretion $(\mathrm{r}=0.85, \mathrm{p}<0 \cdot 001)$ was found in all tests carried out and Figure 5 shows $\Delta \mathrm{ppm}$ values and total $\mathrm{H}_{2}$ excretion in the group of subjects, divided into tolerant and intolerant, to whom $10 \mathrm{~g}$ of sorbitol in $250 \mathrm{ml}$ water were administered. No significant difference was found between

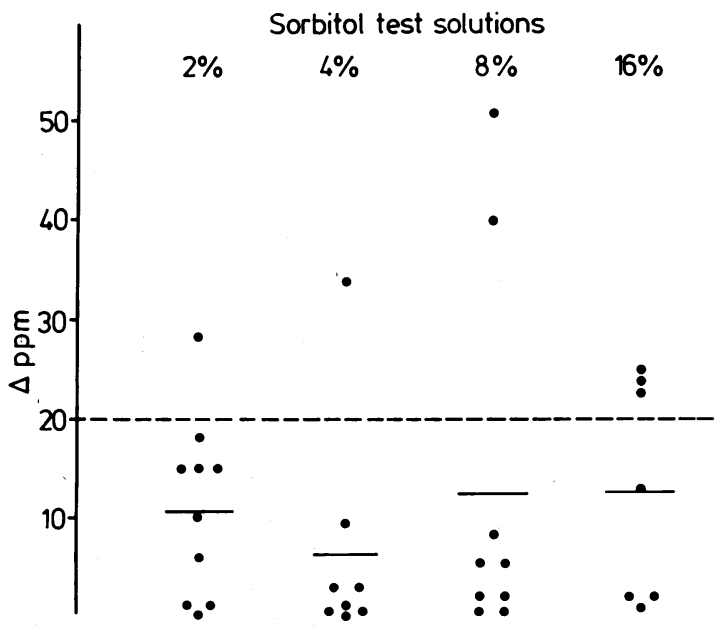

Fig. 3 Maximum increase in breath hydrogen concentration over fasting baseline $(\Delta p p m)$ in healthy volunteers after the ingestion of $5 \mathrm{~g}$ sorbitol test solutions at different concentrations $(2 \%, 4 \%, 8 \%$, and $16 \%)$. Values above the dotted line indicate sorbitol malabsorption.

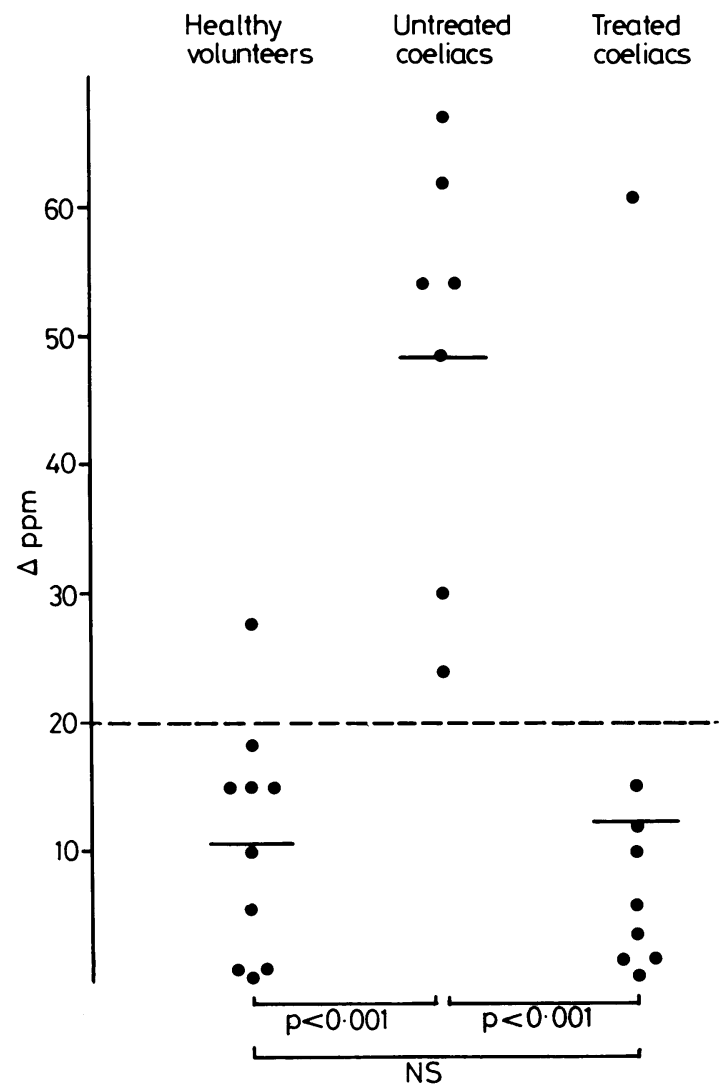

Fig. 4 Maximum increase in breath hydrogen concentration over fasting baseline $(\Delta \mathrm{ppm})$ in 10 healthy subjects, seven untreated coeliac patients and nine coeliac patients on a gluten free diet after the ingestion of $5 \mathrm{~g}$ sorbitol in $250 \mathrm{ml}$ water ( $2 \%$ solution). Values above the dotted line indicate sorbitol malabsorption.

tolerant and intolerant subjects either in $\Delta \mathrm{ppm}$ values or total $\mathrm{H}_{2}$ excretion.

\section{Discussion}

Sorbitol absorption is incomplete ${ }^{4}$ and it is well known that ingestion of $20-30 \mathrm{~g}$ can produce osmotic diarrhoea in most subjects. ${ }^{17}$ According to the recent literature the frequency of malabsorbers, after ingestion of $10 \mathrm{~g}$ sorbitol, ranges from $70 \%-80 \%$, if a rise of $20 \mathrm{ppm}$ is taken as an index of malabsorption. . $^{-11}$ At this dose, even though there was marked intersubject variability in $\mathrm{H}_{2}$ production, we found an even higher frequency of malabsorption $(90 \%)$. It was also found that $10 \%$ of subjects malabsorbed $5 \mathrm{~g}$ and $100 \% 20 \mathrm{~g}$ of sorbitol.

Our results, in agreement with those of other studies, ${ }^{x}{ }^{111}$ seem to confirm that sorbitol malabsorption is dose related. By increasing the dose from 5 to 


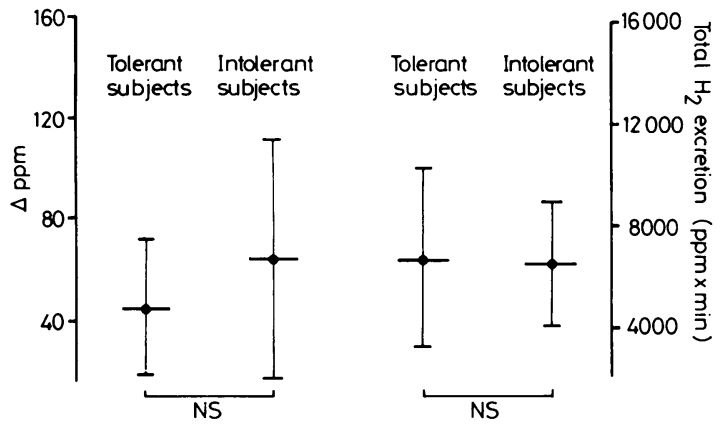

Fig. 5 Breath $\mathrm{H}_{2}$ production evaluated in both mean $\Delta$ ppm and total $\mathrm{H}_{2}$ excretion in 11 tolerant and nine intolerant healthy subjects after ingestion of $10 \mathrm{~g}$ sorbitol in $250 \mathrm{ml}$ water ( $4 \%$ solution).

$20 \mathrm{~g}$ in the same volume of water, however, the concentration of the solution also increases, and we decided to ascertain the effects of different concentrations on malabsorption by administering $5 \mathrm{~g}$ sorbitol at four different concentrations. Our results confirm that on $5 \mathrm{~g}$ sorbitol, by doubling the concentration of the solution from $2 \%$ to $4 \%$ to $8 \%$ to $16 \%$, the frequency of sorbitol malabsorption increases from $10 \%$ to $12 \%$ to $22 \%$ to $43 \%$ respectively, even if this is not accompanied by a proportional increase in $\mathrm{H}_{2}$ excretion. The frequency of malabsorption after ingestion of $6.8 \mathrm{~g}$ sorbitol in the form of four sweets is equal to $62 \%$. The higher frequency of sorbitol malabsorbers on increasing the concentration of the $5 \mathrm{~g}$ solution can be explained by the fact that a hyperosmotic solution speeds intestinal transit and therefore worsens malabsorption. ${ }^{18}$ As our results show that the frequency of malabsorption after a solution of $10 \mathrm{~g}$ sorbitol in $250 \mathrm{mg}(224 \mathrm{mOsm} / \mathrm{kg})$ is greater than after a solution of $5 \mathrm{~g}$ in $31.2 \mathrm{ml}(973$ $\mathrm{mOsm} / \mathrm{kg}$ ), it seems that sorbitol malabsorption depends more on the dose than the osmolality.

In patients with malabsorption as a result of untreated coeliac disease the ingestion of the smallest and least concentrated dose used, $5 \mathrm{~g}$ in a $2 \%$ solution, provoked a highly significant increase in $\mathrm{H}_{2}$ excretion as compared with healthy subjects. All the untreated coeliac patients resulted as sorbitol malabsorbers and this, to a certain extent, was predictable as in villous atrophy there is a reduced absorption of hydrophilic solutes of low molecular weight such as mannitol, another polyhydric alcohol with the same molecular weight as sorbitol $(182 \cdot 17){ }^{10}$ Even though we were unable to evaluate sorbitol intolerance in our coeliac patients, it is possible to speculate that ingestion of even small quantities of sorbitol may worsen symptoms such as bloating, abdominal pain, and diarrhoea.

Of our healthy volunteers, $45 \%$ after ingestion of
$10 \mathrm{~g}$ and $100 \%$ after $20 \mathrm{~g}$ were sorbitol intolerant. No subject showed symptoms of intolerance after ingestion of a $2 \%$ solution of $5 \mathrm{~g}$, however, two of seven $(28 \%)$ did after $5 \mathrm{~g}$ in $16 \%$ solution. Also the severity of intolerance proved to be dose and concentration dependent as the majority of subjects tested suffered from diarrhoea only after $20 \mathrm{~g}$. It must not be forgotten, however, that in the cases of sorbitol intolerance reported in literature, the daily intake of sorbitol varied by only a few grams ${ }^{13}$ to $170 \mathrm{~g}$. $^{12}$

As expected, not all the malabsorbers showed signs of sorbitol intolerance and, in agreement with other studies, ${ }^{89}$ we found no significant correlation between the presence of symptoms and the amount of breath $\mathrm{H}_{2}$ production evaluated either in $\Delta \mathrm{ppm}$ or total $\mathrm{H}_{2}$ excretion over four hours after ingestion of $10 \mathrm{~g}$. This can be explained on the basis of interindividual differences in pain response to gut distension ${ }^{20}$ or in efficiency of 'colonic salvage' of malabsorbed carbohydrates. ${ }^{21}$

In conclusion, our results confirm that nearly all healthy volunteers malabsorb sorbitol at a $10 \mathrm{~g}$ dose and that the percentage of malabsorbers at $5 \mathrm{~g}$ is concentration related.

The increasing use of sorbitol as an artificial sweetener may be clinically relevant ${ }^{y 11-15}$ and recently the need to look closely at sorbitol malabsorption as an important cause of gastrointestinal distress of unknown origin has been emphasised. ${ }^{22}$ At present, there are a large number of dietetic foods and drugs on the market which contain sorbitol in doses and/or concentrations that, according to our study, could cause malabsorption and intolerance (Table). We suggest that habitual consumers of dietetic foods,

\section{Table Sorbitol content of natural and dietetic foods and} drugs

\begin{tabular}{|c|c|}
\hline \\
\hline \multicolumn{2}{|l|}{$\begin{array}{l}\text { Natural foods } \\
\text { Pears }\end{array}$} \\
\hline Prunes, dried & up to $2.4 \mathrm{~g} / 100 \mathrm{~g}$ dry weight ${ }^{\prime}$ \\
\hline Plums & up to $15.8 \mathrm{~g} / 100 \mathrm{~g}^{2}$ ry weight ${ }^{2}$ \\
\hline Sweet cherries & up to $12.6 \mathrm{~g} / 100 \mathrm{~g}$ dry weight ${ }^{2}$ \\
\hline Apple juice (conc) & up to $5.4 \mathrm{~g} / 100 \mathrm{~g}$ fresh weight ${ }^{3}$ \\
\hline Pear juice (conc) & up to $12.0 \mathrm{~g} / 100 \mathrm{~g}$ fresh weight ${ }^{3}$ \\
\hline Dietetic foods* & \\
\hline Sugar free gum & up to $2.5 \mathrm{~g} /$ piece \\
\hline Sugar free mints & up to $2 \cdot 0 \mathrm{~g} /$ piece \\
\hline Diabetic jams & up to $57.0 \mathrm{~g} / 100 \mathrm{~g}$ \\
\hline Diabetic chocolate & up to $40 \cdot 0 \mathrm{~g} / 100 \mathrm{~g}$ \\
\hline Drugs (syrups) $\dagger$ & \\
\hline Multivitamins & up to $8.0 \mathrm{~g} / \mathrm{dose}(53 \%$ solutions $)$ \\
\hline Bronchodilators & $5.0 \mathrm{~g} /$ dose $(50 \%$ solutions $)$ \\
\hline Expectorants & $.7 \mathrm{~g} /$ dose $(57 \%$ solution \\
\hline
\end{tabular}

${ }^{*}$ Products commercially available in Italy; + Contents declared by the Italian pharmaceutical companies (Repertorio Farmaceutico Italiano, 1986). 
diabetics and weight watchers, or users of drugs which contain sorbitol should be better informed, by the producers, about the possible onset of functional bowel complaints. The consumption of sorbitol through non-essential foods, such as chewing-gum and sweets, should be discouraged.

This work was presented in part to the Jubilee Meeting of the British Society of Gastroenterology, London, 1987.

\section{References}

1 Washüttl J, Riederer P, Baucher E. A qualitative and quantitative study of sugar-alcohols in several foods. J Food Sci 1973; 38: 1262-3.

2 Richmond ML, Brandao SCC, Gray JI, et al. Analysis of simple sugars and sorbitol in fruit by high-performance liquid chromatography. J Agric Food Chem 1981; 29: 4-7.

3 Wrolstad RE, Shallenberger RS. Free sugars and sorbitol in fruits. A compilation from the literature. $J$ Assoc Off Anal Chem 1981; 64: 91-103.

4 Mehnert H, Dietze G, Haslbeck M. Zucker und zuckeraustauschstoffe in der diätetik von störungen des kohlenhydratstoffwechsels. Nutr Metabol 1975; 18: suppl. 1: 171-90.

5 Lauwers AM, Daumerie C, Henquin JC. Intestinal absorption of sorbitol and effects of its acute administration on glucose homeostasis in normal rats. $\mathrm{Br} J \mathrm{Nutr}$ 1985; 53: 53-62.

6 Macdonald I, Keyser A, Pacy D. Some effects, in man, of varying the load of glucose, sucrose, fructose, or sorbitol on various metabolites in blood. Am J Clin Nutr 1978; 31: 1305-11.

7 Reynolds JEF. Martindale. The extra pharmacopoeia. 28th ed. London: Pharmaceutical Press, 1982.

8 Hyams JS. Sorbitol intolerance: an unappreciated cause of functional gastrointestinal complaints. Gastroenterology 1983; 84: 30-3.

9 Jain NK, Rosenberg DB, Ulahannan MJ, Glasser MJ, Pitchumoni CS. Sorbitol intolerance in adults. Am J Gastroenterol 1985; 80: 678-81.

10 Hasler W, Tatum D, Owyang C. Fructose and sorbitol malabsorption in normal volunteers. Gastroenterology 1986; $90: 1453$

11 Gryboski JD. Diarrhea from dietetic candies. $N$ Engl J Med 1966; 275: 718.

12 Goldberg L.D, Ditchek NT. Chewing gum diarrhea. Dig Dis 1978; 23: 568 .

13 Hyams JS. Chronic abdominal pain caused by sorbitol malabsorption. J Pediatr 1982; 100: 772-3.

14 Ravry MJR. Dietetic food diarrhea. JAMA 1980; 244: 270.

15 Charney EB, Bodurtha JN. Intractable diarrhea associated with the use of sorbitol. J Pediatr 1981; 98: 157-8.

16 Kotler DP, Holt PR, Rosensweig NS. Modification of the breath hydrogen test: increased sensitivity for the detection of carbohydrate malabsorption. J Lab Clin Med 1982; 100: 798-805.

17 Ellis FW, Krantz JC. Sugar alcohols. XXII. Metabolism and toxicity studies with mannitol and sorbitol in man and animals. $J$ Biol Chem 1941 ; 141: 147-54.

18 Bond $\mathrm{JH}$, Levitt MD. Investigation of small bowel transit time in man utilizing pulmonary hydrogen $\left(\mathrm{H}_{2}\right)$ measurements. J Lab Clin Med 1975; 85: 546-55.

19 Cobden I, Rothwell J, Axon ATR. Intestinal permeability and screening test for coeliac disease. Gut 1980; 21: $512-8$.

20 Lasser RB, Bond JH, Levitt MD. The role of intestinal gas in functional abdominal pain. $N$ Engl J Med 1975; 293: 524-6.

21 Bond $\mathrm{JH}$, Bradley EC, Buchwald $\mathrm{H}$, Levitt MD. Colonic conservation of malabsorbed carbohydrate. Gastroenterology 1980; 78: 444-7.

22 Greenberger NJ. Changes in gastroenterology 19601985. Lessons from the past and implications for the future. The presidential address. Gastroenterology 1985; 89: 933-8. 